PLEASE NOTE! THIS IS SELF-ARCHIVED VERSION OF THE ORIGINAL ARTICLE

To cite this Article: K. Komulainen, P. Tani, T. Ylikoski (2017) FACILITATING THE TRANSITION TO HIGHER EDUCATION WITH A DIGITAL PATHWAY, ICERI2017 Proceedings, pp. 481-485.

doi: $10.21125 /$ iceri.2017.0196

URL: https://library.iated.org/view/KOMULAINEN2017FAC 


\title{
FACILITATING THE TRANSITION TO HIGHER EDUCATION WITH A DIGITAL PATHWAY
}

\author{
Kati Komulainen, Petri Tani, Teemu Ylikoski \\ Laurea University of Applied Sciences (FINLAND)
}

\begin{abstract}
Digitalization is an important enabler for cooperation in teaching between educational levels. Higher education providers, secondary schools and vocational schools now have the means to develop shared learning offerings that harness the power of e-learning. These ventures aim to provide students with flexible learning opportunities that cross borders in the educational system. A key objective is to create a simple path for students transitioning to higher education, reducing the overall time spent in studies before students enter the work market. Study modules in higher education are being brought as a part of secondary and vocational degrees with a digital framework.
\end{abstract}

In the future, higher education institutes need to produce e-learning modules that can be integrated as a part of secondary and vocational degrees. The idea is to lower thresholds in transition to HE. This takes place as students become familiarized with studies in $\mathrm{HE}$ at an earlier age, and also acquire some of the skills needed in HE well before entering that stage. These cross-system opportunities are an important part of generating attraction among students finishing their studies and contemplating further education opportunities.

Laurea University of Applied Sciences in Finland has been developing a digital pathway for secondary and vocational school students, who are transitioning to higher education. Experiences with the pathway have been positive. In 2016, we started a joint project with the City of Espoo where the framework was brought to the students of the City's upper secondary schools.

Simultaneously, we wanted to investigate the utilization of e-learning tools in learning, student guidance, and other parts that specifically meet the needs of upper secondary schools' students. The project has provided an opportunity to share experiences and design a descriptive model of teaching co-operation between upper secondary schools and a university of applied sciences.

The project also aims to improve the digital competences in teaching staff and the assessment of learning and guidance methods. E-learning provides substantial advantages towards more effective teaching. It also assists in creating flexible learning opportunities for students and can bring the HE learning smorgasbord to upper secondary students, without the limitations of time and place.

One aim of the Ministry of Education's agenda has been to reduce the overall time spent in education. We hope to provide one way to meet the goal. In our framework, a secondary or vocational school student has access to a range of higher education studies. She then takes a sufficient amount of this selection as a part of her degree. When the student later enters a higher education institution, these prior studies are recognized as a part of her HE degree. As a result, we are building a working pathway towards higher education that eases the transition and reduces the total length of the student's education.

Although both secondary and vocational degrees provide eligibility for higher education in Finland, this is no longer sufficient. The demands of the society require new innovations of the educational system to meet national goals in competitiveness. Moreover, our pilot project shows implications that a student's ability to continue her studies in HE is improved if her previous secondary or vocational degree has encompassed some HE studies.

\section{INTRODUCTION}

Digitalization is an overarching issue that touches various issues in the society. In Finland, the Finnish Government's strategic priorities are implemented through a set of key projects. One of the strategic priorities is "knowledge and education". Digitalization is an inherent part of the key projects within knowledge and education, such as "New learning environments and digital materials to comprehensive schools", "Acceleration of transition to working life 
Access to art and culture will be facilitated", and "Cooperation between higher education institutions and business life will be strengthened to bring innovations to the market" (The Finnish Government, 2016).

Through the digitalization of learning environments, the government aims to speed up transition to higher education, facilitate and shorten the studies in higher education, and speed up the transition to work from higher education. This article describes a tailored digital pathway to higher education which is built on an eLearning environment. Its purpose is to help vocational degree students' participation in higher education studies already during their secondary level studies.

Digital transformations assist in the general reform of the educational system as well. Finnish vocational education and training is going through a comprehensive reform. The specific focus of the reform is in students' future competences and in responding to changes occurring across industries. One key objective is to create and offer more individual and unique study paths to students. Digitalization plays a significant role in the reform.

On the other hand, the Finnish Education Evaluation Centre reveals that student transitions and smooth study paths at educational transition phases are in the focus of future quality audits. The audits taking place between 2016 and 2019 will emphasize enhancing smooth transitions between upper secondary school and HE (National Plan for Education 2016 - 2019).

In general, student's ability to graduate faster and gain faster access to the employment market is also an overarching aim. Digital study pathway studies, in this case, are one practical example how to make studies more flexible for both students and future employer organizations. (Ministry of Education and Culture 2017.)

Laurea University of Applied Sciences has six campuses in five cities in the Greater Helsinki Region in Southern Finland. Laurea serves the entire region and its 25 municipalities, where distances can be quite long. Laurea offers degree programs in 12 areas and focuses on producing service innovations and professionally orientated education, regional development and R\&D activities through these areas. Laurea employs approximately 500 personnel and has ca. 8,000 students, of which ca. 1,200 study in adult education programs.

Laurea ranks first in student attraction metrics among universities of applied sciences in Finland. This is largely due to its unique approach to learning. Laurea's curricula are built on a proprietary pedagogical model that relies on authentic working-life cooperation, learning projects, and student activity. It can take multiple forms, but most often it manifests in real development projects that students handle for Laurea's working life partners. This is potentially one reason why Laurea is a very popular option among vocational degree students seeking to continue studies. In general, over half of the new students in Laurea have a vocational background. Also, as a result of the orientation, postdegree employment is very high; generally, over $95 \%$.

\section{DESCRIPTION OF THE PILOT PROJECT}

In the pilot project, we have built a tailored digital pathway for studies aiming to a degree. It is designed for a student in secondary or vocational studies who already has an idea of her future degree, such as registered nurse or bachelor of social services. In Finland, application to the studies is possible with a secondary degree or a vocational degree. There is no generally available data on how many of these students have an idea of a future career path. However, for those that do, the digital pathway offers an excellent opportunity.

The digital pathway consists of e-Learning modules that can be integrated as a part of secondary and vocational degrees but that are taken from Laurea's curricula. Students have the ability to try out learning in an HE through a lower threshold program. The students can include the study modules in their secondary or vocational degree. If the student later applies to higher education, she can include the modules in that degree through recognition of prior knowledge.

The studies are offered in packages that are designed with the student in mind. The packages are also built in parallel to future options within higher education. This will give the student more exposure to different alternatives. Finally, the pathway features a special tutoring and support system to help in all issues. Time management, technical issues and the demands of higher education are but some of the potential hurdles students may face. All are tackled with a support system relying on peer to peer support. 
The idea of the pathway is to lower thresholds in transition to higher education through familiarization in practice, and through acquiring some of the skills needed in HE. This will also shorten the total time needed in studies, as a part of the study modules can be included in two degrees.

The 21st century has witnessed the advancement of learning technologies, especially with e-learning. E-learning facilitates learning with easier accessibility to studies through the use of digital platforms and different devices such as tablets and smartphones. In regions where studying used to require substantial travel or even moving to another city, e-learning can have dramatic impacts.

Students are often enthusiastic about the new innovations in learning, possibly as their daily lives tend to revolve around various digital services and social media platforms anyway. When a person's life is seamlessly analog and digital, a need for an adaptive learning experience becomes paramount. Elearning can take on a number of forms, depending on the context, subject matter, student needs and the educator's preferences. Typical options are course management systems, social media, sites, wikis, apps, chat and video calls (see Ipaye 2011 for a discussion). The physical premises of an educational establishment are no longer necessary.

Another reason for the increasing popularity of e-learning is the knowledge explosion that we are facing. Digitalization of information and a wide availability of digital knowledge changes the shape and form of learning. In many areas, it is becoming more important to know how to handle large amounts of information. E-learning supports this pedagogy inherently well.

In Finland, the development of e-learning paths has been rapid. Attention has been paid to how educational structures and guidance staff can support students. Tutoring and alumni support are frequently used. This is important, as tutoring and guidance have different challenges in e-learning.

For this reason, we focused on how new technologies provide new methods for supporting students. We can construct functionalities to boost the process by using learners' digital footprints in educational institutions' systems. Through learning analytics, we are anticipating support needs, clarifying differences between students and improving the competences of special needs students. To avoid students' negative experiences, student guidance plays a major role. According to O'Kane (2014), it is important to strive to create a positive learning experience. We do not teach; we facilitate, guide and conduct the learning process.

The digital pathway is a service for the student that offers smooth and flexible options, more diverse options, an ability to try out HE studies, and the eventual possibility to reduce time in studies. This is only the top of the iceberg, however. For the secondary or vocational school, it is a way to support student attraction and a cost-efficient way to broaden the study offering. For the HE institution, it is a way to implement the task of regional impact that the Finnish law requires.

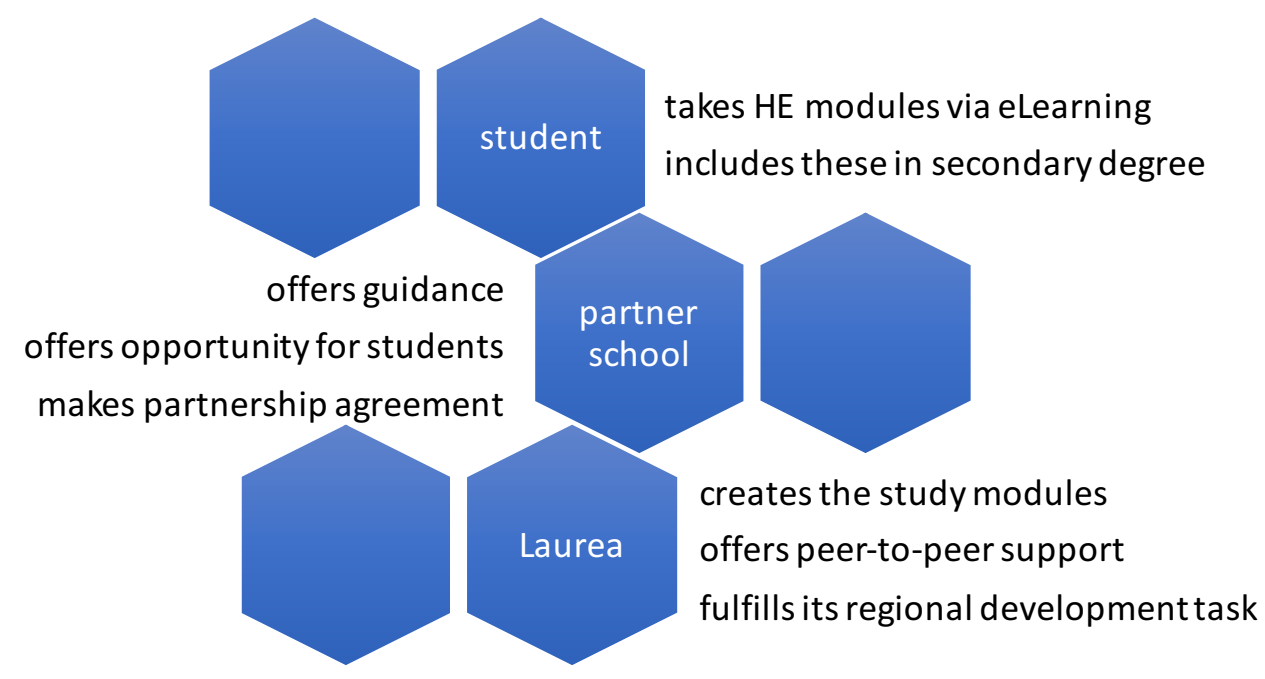

Figure 1. The Digital Pathway in action.

Currently, the digital pathway is available in eight degree programs in Laurea ranging from business to nursing and social services to security. Studies within the digital pathway consist of substance matter as well as general applied science material. 
As the pathway requires a high amount of involvement of the student, and a consistent individual study approach, it is important that the student counselor is in close cooperation through the program.

\section{ASSESSMENT OF THE DIGITAL PATHWAY}

The first experiences of the pilot project are quite positive. The digital pathway has been successful on three fronts: first, the studies offered within the pathway were chosen from a digital learning portfolio. This made it possible for the secondary and vocational school students to participate in Laurea's studies in between their own schedules. Secondly, the pathway has been designed to allow for possible future options within degrees. And thirdly, peer to peer support and fortified tutoring have been found essential for success in the studies.

Some of the challenges that we have found are related to e-learning in general. The need for selfguidance and the general requirements of e-learning pedagogy have caused difficulty for some students. On the other hand, these are often highly individual and similar issues cause problems among university students as well.

Self-expression and writing skills are paramount in e-learning. This can be quite different to the methods used for recording skills in face-to-face learning. These have been areas where students have needed extra support and encouragement during the project.

The pilot has provided teachers in the secondary and vocational schools as well as in higher education with skills in learning from another institute's working culture and sharing knowledge in e-learning pedagogy. Also, a new networked way of building an operation together and an improved understanding of curricula have been positive experiences.

The benefits of the project can be seen from the perspectives of the student, the participating secondary or vocational institute, or the higher education institute (Laurea in this case).

Figure 2. Benefits of the Digital Pathway for participants.

\begin{tabular}{|c|c|c|}
\hline Student & $\begin{array}{l}\text { Partner organization } \\
\text { (secondary or vocational) }\end{array}$ & $\begin{array}{l}\text { Higher education provider } \\
\text { (Laurea) }\end{array}$ \\
\hline $\begin{array}{l}\text { Possibility to try out higher } \\
\text { education studies }\end{array}$ & Supports individual study paths & $\begin{array}{l}\text { Closer partnerships with } \\
\text { secondary and vocational } \\
\text { providers }\end{array}$ \\
\hline $\begin{array}{l}\text { Higher education studies as part } \\
\text { of a secondary degree }\end{array}$ & $\begin{array}{l}\text { Supports student and staff e- } \\
\text { Learning skill acquisition }\end{array}$ & Improved digitalization \\
\hline Shorter overall study time & Stronger regional position & $\begin{array}{l}\text { Regional impact and community } \\
\text { outreach }\end{array}$ \\
\hline Faster transition to work & An extended digital offering & $\begin{array}{l}\text { Improving staff skills in } \\
\text { digitalization }\end{array}$ \\
\hline Improved e-Learning skills & Career guidance & New potential student pool \\
\hline
\end{tabular}

The choice of a place to study is a complex social process. On a more theoretical note, the digital pathway offers an opportunity to open another educational community to the student. This will allow her to gain a realistic perspective and experience of studying in another institute. The opportunity to try out studies in higher education is a value in itself, as it gives the person an opportunity to gain firsthand experience without the typical social pressures (Holmegaard, Ulriksen \& Madsen 2014.)

\section{CONCLUSIONS AND RECOMMENDATIONS}

According to our experiences, the digital pathway from secondary studies to higher education is a promising and meaningful option for students. For the students, the option seems to increase motivation and a future orientation relating to the student's current studies as well as future study choices.

For a student with a clear educational goal, the digital pathway offers an option to try out higher education studies, preparing oneself to future entrance exams, reduce the overall time spent in education, and consequently, speed up the transition to work. 
For a participating staff member, the digital pathway is an opportunity to advance digital interactive learning between secondary studies and higher education. During the project, awareness and understanding of the possibilities, tools and openness of e-learning has increased substantially.

The studies during the pilot project have been related to both substance matter and general skills needed in higher education. The content and structure of the studies need to be assessed thoroughly. While it seems that subject matter appears to motivate the students, general HE skills are also highly beneficial in that they contribute to the student's general readiness and will improve embracing the subject matter as well.

The number of participants in the pilot have been relatively small. The purpose is to increase the availability of the digital pathway to a larger geographical area, including smaller municipalities in rural areas. This may help restore and maintain the vitality of secondary education in regions with negative population relocation issues. This is an option to improve equality in education and increase the availability of education, wherever and whenever needed.

\section{REFERENCES}

[1] Ministry of Education and Culture 2017. Vocational education and training will be reformed to meet the needs of students and working life. http://minedu.fi/artikkeli/-

lasset_publisher/ammatillisen-koulutuksen-reformi-uudistaa-koulutuksen-vastaamaanopiskelijoiden-ja-tyoelaman-tarpeita?_101_INSTANCE_0R8wCyp3oebu_languageld=en_US 16.9.2017.

[2] National plan for education evaluation 2016 - 2019. 016. Finnish Education Evaluation Centre. https://karvi.fi/app/uploads/2016/06/National-Plan-for-Education-Evaluations-2016-2019.pdf 16.9.2017.

[3] The Finnish Government 2016. http://valtioneuvosto.fi/documents/10184/321857/Toimintasuunnitelma+strategisen+hallitusohjel man+k\%C3\%A4rkihankkeiden+ja+reformien+toimeenpanemiseksi+2015\%E2\%80\%932019\%2 C+p\%C3\%A4ivitys+2016/305dcb6c-c9f8-4aca-bbbb-1018cd7a1fd8 22.9.2017.

[4] Holmegaard, H.T, Ulriksen L.M. \& Madsen L.M. 2014. The process of choosing what to study: a longitudinal study of upper secondary student's identity work when choosing higher education. 58 (1) Scandinavian Journal of Educational Research.

[5] Ipaye, B. 2011. E-Learning in a Nigerian open university. http://linc.mit.edu/linc2010/proceedings/session1/paye.pdf (June 16, 2011).

[6] O'Kane, K. 2014. Positive and Negative Learning Experiences. http://sheilaokane.weebly.com/uploads/2/6/1/8/26183300/positive_and_negative_learning_expe riences_paper.pdf 17.5.2014. 